\title{
Red is the new blue - The role of color, building integration and country-of-origin in homeowners' preferences for residential photovoltaics
}

\author{
Stefanie Lena Hille*, Hans Christoph Curtius, Rolf Wüstenhagen \\ University of St. Gallen, Institute for Economy and the Environment, Tigerbergstrasse 2, 9000 St. Gallen, Switzerland
}

\section{A R T I C L E I N F O}

\section{Article history:}

Received 27 January 2017

Received in revised form 17 August 2017

Accepted 30 November 2017

Available online 14 December 2017

\section{Keywords:}

Solar photovoltaics

Building-integrated photovoltaics

BIPV

Consumer preferences

Country-of-origin effect

Adaptive choice-based conjoint

\begin{abstract}
A B S T R A C T
The wider diffusion of solar photovoltaics (PV) is crucial to lower the environmental impact of the residential sector, which is responsible for a large share of energy consumption in many industrialized countries, including Switzerland. By conducting an adaptive choice-based conjoint (ACBC) with a representative sample of Swiss homeowners planning to undertake a roof renovation project, we investigate the extent to which financial and non-financial factors drive homeowners' preferences for PV in Switzerland. We reveal that the color and country of origin of the PV modules are the main drivers for increasing share of preference for PV. In addition, we estimate the price premium that homeowners are willing to pay for building-integrated PV (BIPV) versus rack-mounted PV. We find a premium in willingness to pay of $21.79 \%$ for a roof with a BIPV installation in comparison with a rack-mounted PV installation. We further show that an increase in revenues from electricity sales (e.g. via feed-in tariffs), when transparently disclosed over an aggregated time frame, would be almost equally effective in spurring demand for PV as a decrease of initial investment costs (e.g. via one-off investment grants). Implications for energy policy and marketing are discussed.
\end{abstract}

(c) 2017 Elsevier B.V. All rights reserved.

\section{Introduction}

The Intergovernmental Panel on Climate Change (IPCC) contends that the extremely likely ${ }^{1}$ dominant cause of the observed global warming since the mid-twentieth century is, together with other anthropogenic drivers, anthropogenic greenhouse gas emissions [1]. The urgency of climate change, the pressure on policy makers from international climate negotiations and civil society, and the prospect of greater independence of energy imports have provoked political support and unprecedented growth of renewable energy technologies globally. Meanwhile, renewables are the second-largest contributor to global electricity production [2]. Though still representing a small proportion, solar photovoltaics (PV) have by far the fastest annual growth rates [2].

The wider diffusion of PV is particularly crucial to lower the environmental impact of the residential sector, which is responsible for a large share (approximately $31 \%$ ) of total final energy consumption

\footnotetext{
* Corresponding author.

E-mail addresses: stefanie.hille@unisg.ch (S.L. Hille), hans.curtius@unisg.ch (H.C. Curtius), rolf.wuestenhagen@unisg.ch (R. Wüstenhagen).

1 The term extremely likely has been used to indicate the likelihood of 95\%-100\% of the outcome [1].
}

in Switzerland [3]. PV in the residential area is commonly rackmounted on top of an established building (building-attached PV), whereas PV systems integrated into the shell of a building, called building-integrated PV (BIPV), represent only a niche market so far [4]. However, BIPV provide the opportunity for a more upscale architectural design, as they are an integral construction element of a building. BIPV can avoid disruptive visible changes in a building's appearance, while also serving as a new architectural design element with increased aesthetical value for homeowners. Given the many benefits of BIPV, market analysts therefore foresee enormous growth potential in the global BIPV market in the future [5-9].

The contribution of this study is threefold:

1. First, given that BIPV provides the opportunity for a more upscale architectural design than traditional rack-mounted PV plants, we aim to identify, by use of an adaptive choice-based conjoint (ACBC) survey, whether and how much more Swiss residential home owners planning to undergo a roof retrofit are willing to pay for a roof retrofit with a BIPV plant installed than for a roof retrofit with a separate rack-mounted PV plant installed on top.

2. Second, we are interested in what factors, including financial and non-financial, might drive preferences for solar PV among residential homeowners in Switzerland. For this purpose, we perform a series of sensitivity runs in which we change the level 
Table 1

Attributes and attribute levels used in the ACBC.

\begin{tabular}{|c|c|c|c|}
\hline Attribute & Attribute levels & & \\
\hline Roof type (+ base price) & Standard roof/no PV (+ 15,000 CHF $)$ & Rack-mounted PV (+ 40,000 CHF) & $\mathrm{BIPV}(+40,000 \mathrm{CHF})$ \\
\hline Color of the PV plant/roof & Blue & Red & Black \\
\hline Origin of PV panels & China & Germany & Switzerland \\
\hline Investment costs & \multicolumn{3}{|c|}{ Depending on the roof type + random variation to the price shown of $-30 \%$ to $+30 \%$. } \\
\hline $\begin{array}{l}\text { Revenues from electricity sales/reduction in } \\
\text { electricity costs over } 20 \text { years }\end{array}$ & $-20,000 \mathrm{CHF}$ & $-30,000 \mathrm{CHF}$ & $-40,000 \mathrm{CHF}$ \\
\hline Purchase premium & Rebate of $1000 \mathrm{CHF}$ & Participation in an e-car raffle to win a Tesla & Free e-bike \\
\hline
\end{tabular}

of one factor (e.g. the color of the PV panels) to estimate how such a change influences homeowners' preferences for a PV plant in the course of the next planned roof retrofit project.

3. Third, we also aim to contribute to the energy policy literature on government subsidies. In Switzerland, different kinds of government subsidies are available, including one-off investment grants, which cover a significant part of the cost of an installation, and feed-in tariffs, in which a cost-based price is paid for the renewable electricity supplied to the grid. Previous research on barriers related to PV adoption in Switzerland has shown that homeowners tend to regard upfront investment costs as more important than a reduction in electricity costs from not purchasing electricity from the grid or an increase in earnings from electricity sales to the grid [10]. We therefore imply that consumers would prefer one-off investment grants (which would lower upfront investment costs) to feed-in tariffs (which would increase earnings from selling self-produced electricity to the grid). We investigate whether feed-in tariffs could be made equally effective in spurring demand for PV as one-off grants if future potential earnings from electricity sales would be transparently disclosed over an aggregated time frame of 20 years (a method known as "temporal reframing").

The rest of the paper proceeds as follows: In Section 2, we provide information on the design of the study and discuss our chosen methodological approach. In Section 3, we provide an overview of our empirical findings. Section 4 concludes.

\section{Methodological approach}

\subsection{Structure of the survey}

We used Sawtooth Software's module SSI Web to program the survey. The survey consisted of four different sections. First, we placed several screening sections at the beginning of the survey with the aim to identify whether homeowners fulfilled our criteria for eligibility to participate in the survey (see Section 2.5). Second, we continued with the core element of the study, an ACBC, which we describe in detail in Section 2.2. Third, the survey continued by asking respondents about a range of different questions to examine a set of motivators for and barriers to the further diffusion of PV in Switzerland. ${ }^{2}$ In the last part of the questionnaire, the respondents answered a set of demographic questions (see Section 2.6).

\section{2. $A C B C$ analysis}

Homeowners' preferences can be evaluated by analyzing stated or revealed preference data. Given that PV in Switzerland is in the early phase of the diffusion process, appropriate revealed preference data to evaluate consumer preferences and market potential are unavailable for this purpose. We therefore built our empiri-

2 We address and report the results of this part of the survey in a separate paper ${ }^{2} \mathrm{We}$ cal approach around a data set of stated preferences, for which we used choice experiments as the methodological approach. This technique is intended to elicit people's preferences for different characteristics, or attributes, of a product in an indirect way. This is done by describing a product or service in terms of different attributes and requiring respondents to evaluate a series of different choice tasks, by performing trade-offs between those attributes [11]. Several studies have applied choice experiments in the area of sustainability and energy [12-23].

We applied an adaptive $A C B C$ method, which adapts the interview flow to the respondents' preferences and is especially appropriate for examining preferences when people make use of non-compensatory decision-making [24,25]. Non-compensatory decision-making takes place when people evaluate alternatives by first excluding the product profiles made up of combinations of attributes and attribute levels that contain characteristics unacceptable to them (e.g. a too high price) and then choosing among the remaining product options in line with those so-called screening rules [24]. Several researchers have used this relatively new methodology in the past few years (e.g., [26-31].

\subsection{Selection of attributes and attribute levels}

The ACBC survey asked respondents to evaluate and choose among different roof retrofit options in the context of their planned roof retrofit project. The different roof retrofit options differed depending on whether only standard roof tiles were used for roof covering or the roof also included a roof-top PV system. The different roof retrofit options also differed in the set of characteristics (e.g. investment costs). As a first step in the setup of the ACBC, we chose six different attributes and corresponding attribute levels for inclusion in the study that characterized an individual roof retrofit option. An attribute is a feature of a roof retrofit option (e.g. investment costs) comprising a range of attribute levels of that specific feature (e.g. different price levels). We aimed to select attributes and attribute levels to establish realistic choice scenarios, on the one hand, and to elicit homeowners' preferences for some attribute levels with high relevance for marketing and policy implications, on the other hand. The attributes and attribute levels of the roof options selected for the ACBC are based on consultations with stakeholders, a broad literature review, and a review of product catalogues used for marketing purposes. In addition, a pre-test with experts and colleagues, as well as a small-scale pilot survey with 25 homeowners, confirmed the relevance and suitability of the chosen attributes and levels. Table 1 provides an overview of the six attributes and the corresponding attribute levels used in the ACBC.

We included the attribute "roof type" with three different rooftype options, including the option of a roof with standard roof tiles (the "Standard roof/no PV" option), the option of a roof with roof tiles and a separate rack-mounted PV plant installed on top (the "Rack-mounted PV" option), and the option of a roof with a BIPV plant installed in which the PV panels replace the need for any roof tiles (the "BIPV" option). As a second attribute, we included levels of the color of the PV plant or roof (i.e., blue, red, or black) 
to assess homeowners' preferences for different colors. Despite the good technical functionality of colored PV modules [32], such modules have found little application in the market so far and thus have not helped overcome the general skepticism about PV by architects [33]. We therefore were interested in determining whether the different colors would positively affect homeowner's acceptance of PV in the Swiss market. Demonstrating the positive impact of color in influencing homeowners to opt for a PV plant could be beneficial for convincing architects to adopt PV in property development. We made use of conditional displays that included a picture of the respective roof option based on the two attributes "roof type" and "color of the PV plant/roof", resulting in a total of $3 \times 3=9$ combinations (see Appendix A Fig. A1 for an overview of all nine graphics).

For the attribute "investment costs", we made use of the summed pricing option [25], which allowed us to use realistic prices for the different roof retrofit options. To select the relevant price levels, we conducted expert interviews (e.g. with installers) and reviewed marketing documents (e.g. catalogues, websites). With the summed pricing approach, we assigned a base price of 15,000 CHF to the "Standard roof/no PV" option and a base price of 40,000 $\mathrm{CHF}$ for roof retrofit options involving a PV plant. We assumed the same base price for both roof retrofit options including a PV plant, given that the PV modules of the BIPV system can be integrated directly into the building envelope and thus can replace parts of conventional building materials (i.e. roof tiles). Although our consulted experts estimated the costs of a BIPV system higher than those of a rack-mounted PV system, the higher costs of the BIPV system can be offset against the cost of the roof tiles that would also need to be replaced during a roof retrofit where a rack-mounted PV plant would be installed on top. To display the total investment costs of the different roof retrofit options, we randomly varied the prices for the different options to the price shown of $-30 \%$ to $+30 \%$. This approach allows a realistic estimation of the price coefficient in which we can disentangle the effect of a price change on respondents' choices in the survey from the price increases we assigned to the different roof types [25]. To avoid uneven prices, we indicated that the investments costs should be rounded to the closest 5000 CHF after having been randomly varied.

In addition to the summed pricing approach, we implemented an alternative-specific conjoint design, as several of the other attributes chosen (e.g., country of origin of PV plant) were not applicable to the "Standard roof/no PV" retrofit option. The alternative-specific design worked well with our research question, as our aim was to test how changes in the characteristics of the PV option would lead people to switch from a standard roof (without a PV plant) to a roof containing a rooftop PV installation.

For the roof retrofit options that contained a rooftop PV installation, we included the attribute "origin of PV panels" with three alternatives (Switzerland, Germany, and China) to investigate the significance of the country-of-origin effect. We included this attribute to build on the vast literature stream in the fields of international business, marketing, and consumer behavior on the country-of-origin effect (e.g., [1,34-39]. Country of origin is often part of the mental shortcut to decision making [40]. Information about country of origin is commonly sought to indirectly infer beliefs about a product's quality characteristics, such as durability $[34,35,41]$. Given that the manufacturing of technical products often demands highly skilled employees, people often believe that high quality can only be secured when the product is produced in a developed country [39]. Swiss consumers commonly assign a high reputation to both Switzerland and Germany for producing high-quality products, given the high supply of skilled workers and research, whereas they attribute lower product competence to China [42].

In addition, for the roof retrofit options that contained a rooftop PV installation, we included the attribute "revenues from electricity sales/reduction in electricity costs over 20 years". Literature shows that high initial investment costs are a common obstacle preventing consumers from purchasing energy-saving products, even though they would recoup the higher initial investment costs through energy savings in the long run (e.g. [43-46]. One explanation for this significant overvaluation of initially higher investment costs is that consumers are often not capable of determining the possible cost savings of such investments because of a lack of information. Thus, we provided respondents with information about the level of reduction in electricity costs by not purchasing electricity from the grid and possible revenues from selling self-produced electricity to the grid through feed-in tariffs that they could reach by installing a PV plant, to investigate whether disclosing such information could address the barrier of overvaluation of investment costs. Mouseover pop-ups in the survey presented further details about this attribute. We included the information that in case homeowners opted for a roof retrofit containing a PV installation, they could produce their own electricity, which they would then be able to sell to an electricity provider (and thus make money) or consume themselves (and thus need less electricity from their power provider in the future). We informed the respondents that the cost savings or respectively the earnings were dependent on the efficiency of the PV plant, possible support schemes (e.g. feed-in tariffs from the government), and any occurring maintenance costs. We decided to provide the information over an aggregated period (i.e., 20 years), given that research has shown that a longer time frame in which such information is presented is particularly likely to reduce the scale of over-discounting (e.g. [47,48]. The attribute included three levels: $-20,000 \mathrm{CHF},-30,000 \mathrm{CHF}$, and $-40,000 \mathrm{CHF}$. We explicitly decided to use a negative sign when presenting this information because pre-tests showed that some respondents would otherwise add those values as costs on top of the investment costs.

Finally, we also included the attribute "purchase premium" to investigate the effectiveness of marketing tools, such as different rewards versus a rebate. We applied insights from psychology and behavioral economics to determine whether the type of incentives with about equal benefits would exert a different impact on homeowners' choices for a PV roof option. In particular, we were interested in the difference between a lottery-based incentive (i.e. possibility to participate in a raffle with the chance to win a Tesla electric car) and a fixed incentive (i.e. rebate of $1000 \mathrm{CHF}$ ). Prior research has shown that lotteries exploit consumers' inclination for overrating small percentages in view of large possible rewards $[49,50]$. Evidence also reveals the effectiveness of lottery incentives in a wide range of domains (e.g. [49,51-53]. In a similar vein, we aimed to investigate the impact of a rebate of $1000 \mathrm{CHF}$ versus a free electric bike. Previous research has provided evidence of the "zeroprice effect", showing that consumers often overreact to things that are free (e.g. free promotions, product giveaways) [54-56].

\subsection{Overview of the $A C B C$ interview}

The ACBC section of the survey started with a screening section, in which respondents were presented repeatedly with four different roof retrofit options at a time and asked to indicate whether they considered the different retrofit options "a possibility" or not (see Fig. 1 for an example of such a screening task). In the screening section, the surveyed homeowners needed to evaluate the different roof retrofit options in isolation but did not need to make a choice among the three options. We screened the homeowners' responses to identify whether they applied any non-compensatory screening rules. Such a screening rule would apply, for example, if a respondent consistently excluded some roof retrofit options not containing a PV installation and only chose options containing either a rack-mounted PV or a BIPV installation. If that were the case, the respondent would be asked explicitly whether a "Stan- 


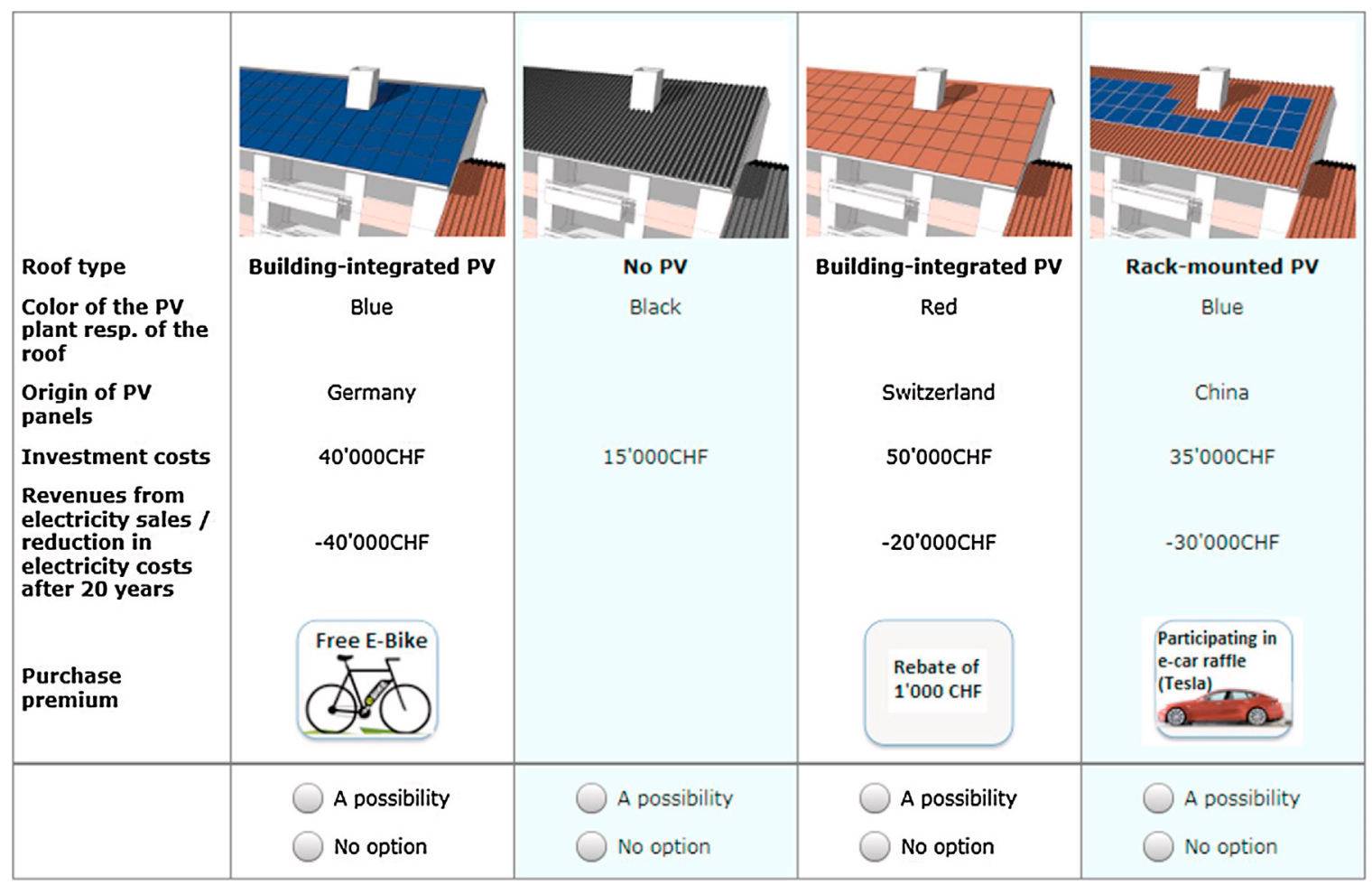

Fig. 1. Example of a screening task (translated; original in German and French).

dard roof/no PV" retrofit option would be an unacceptable option to them.

In the second section of the ACBC, homeowners were then presented with a set of different choice tasks. In this choice task section, respondents were asked to make a choice among three presented roof retrofit options. Only concepts considered "possibilities" in the previous section appeared in this choice task section (see Fig. 2 for an example of a choice task). To simplify the comparison among the different roof retrofit options and to reduce the cognitive difficulty of the task, the roof retrofit options frequently shared some characteristics, such that one or more rows were "grayed out" to help respondents focus on the remaining differences of the roof retrofit options [24].

\subsection{Target population}

The main target group of this study was individuals planning to make a roof retrofit decision within the next 10 years. Thus, as a core element of the study, the survey took place in the context of real decision-making. We therefore explicitly invited homeowners only and excluded tenants. Furthermore, only homeowners who either owned a single-family house or a building with a maximum of five units were able to take the survey. The reason for this decision was that the specific setup of our ACBC survey with the two attributes (1) investment costs and (2) revenues from electricity sales/reduction in electricity costs over 20 years included absolute monetary figures; the values used in our survey would not be realistic for buildings with more than five units, given that such buildings typically come with larger roofs that require higher investment volumes. Homeowners were explicitly asked in a filter question whether they were actively involved in the house retrofit decisions. Only those who affirmed their involvement were finally asked to complete the survey. In addition, only those who owned a building with a pitched roof were able to take the ACBC survey; we excluded those owning a house with a flat roof from the survey. The reason for this decision was the nature of BIPV systems, which is not very suitable for flat roofs. We assigned a professional translation agency to translate the survey from German to French to invite both German- and French-speaking participants from Switzerland to take the survey.

The respondents in the study were recruited from an online access panel consisting of more than 50,000 registered participants in Switzerland maintained by the Swiss market research company Intervista AG. The market research company compensated respondents for taking part in the study, which took place between January and February 2016. To achieve a representative sample of our envisaged target group, the market research company first recruited a representative sample of 6104 respondents from Switzerland. The sample was drawn by quota sampling, considering gender, age, language region, and home ownership. In total, 408 completed datasets were available by homeowners that were able to pass the filter questions, described in the response funnel displayed in Fig. 3.

\subsection{Sample characteristics}

Table 2 displays the details regarding the composition of the 6104 participants who were invited to take the survey before the additional filter questions were applied. When comparing the characteristics of those respondents with national data from the Swiss Federal Statistical Office, we show that the overall sample is representative to the Swiss population in terms of gender, age, language region, and home ownership.

Table 3 presents the demographic details of those respondents who have passed the filter questions and who subsequently took part in the ACBC part of the survey. Given that the whole sample of 6104 survey respondents is representative of Switzerland, we consider the sample of 408 respondents who participated in the ACBC also representative to our population of interest (i.e. those that have passed the filter questions). When comparing the characteristics of the 408 respondents with national data from the Swiss Federal Statistical Office, we show that our final subsample that passed the four filter questions differs from the Swiss population 


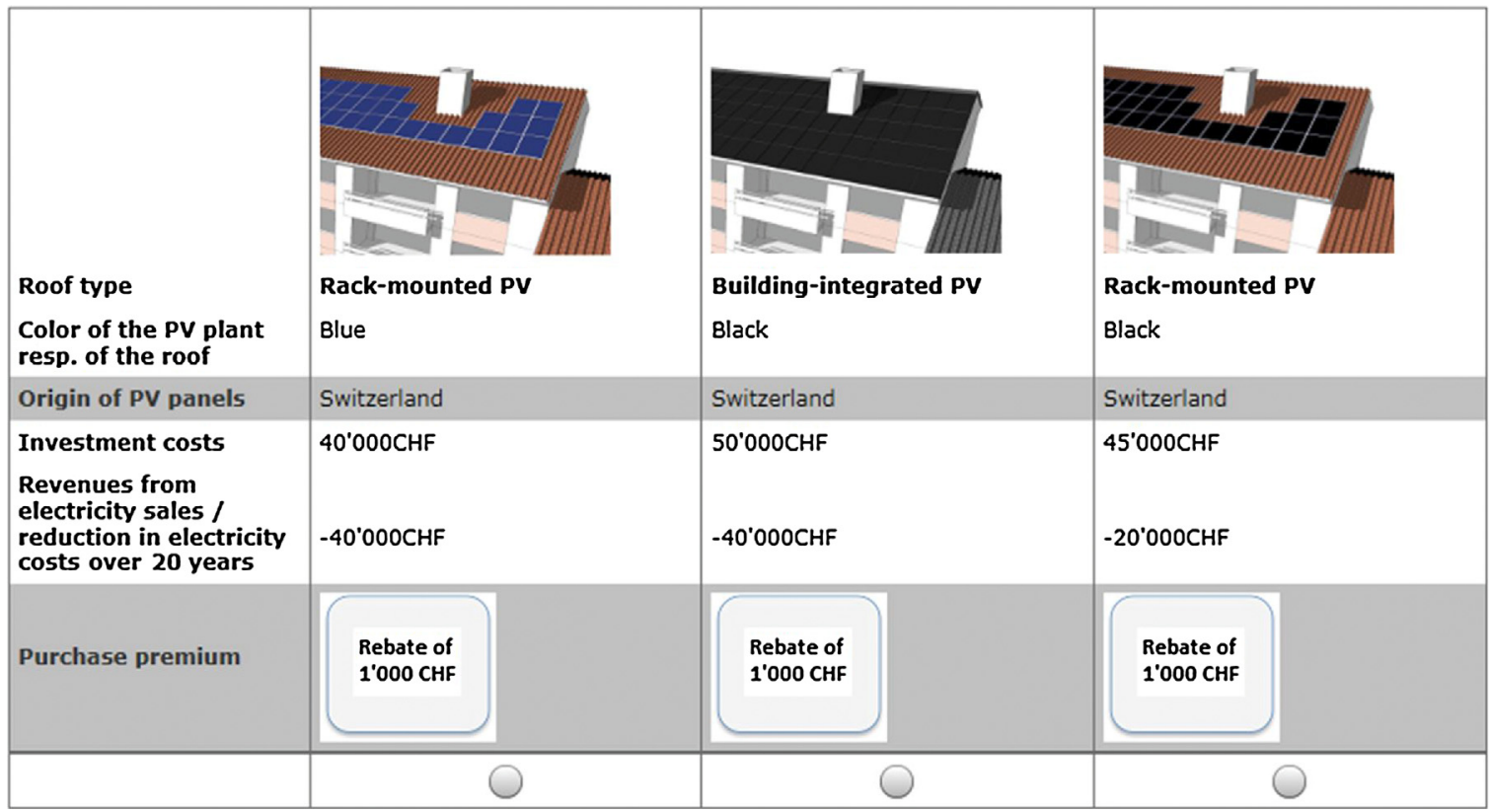

Fig. 2. Example of a choice task (translated; original in German and French).

$>50,000$ citizens - online access panel of a market research agency in Switzerland

Screen-out

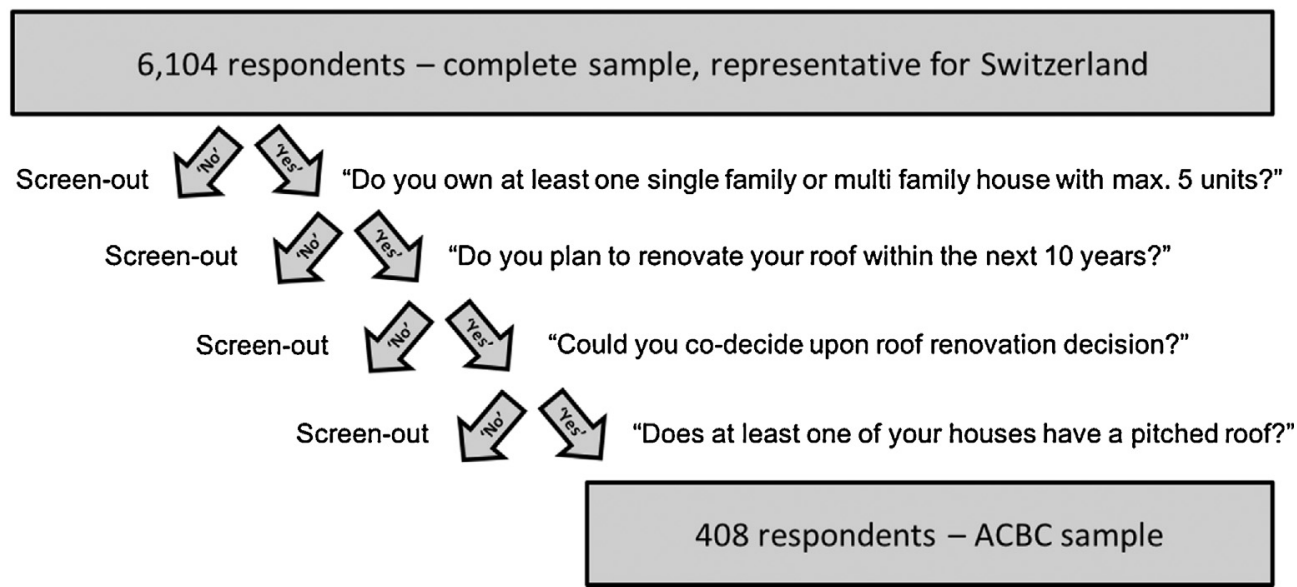

Fig. 3. Target population and response funnel.

in terms of gender and age (see Table 3). Thus, the final ACBC sample of homeowners that passed the filter questions is older than the overall Swiss population and exhibits an overall higher share of men.

\section{Results and discussion}

\subsection{Results of the hierarchical Bayes model}

We used hierarchical Bayes (HB) to derive part-worth utilities of individual respondents based on the data collected in the survey $[59,60]$. With an HB model, it is possible to measure respondent heterogeneity that acknowledges variances in preferences between respondents, which is often useful for market simulation purposes. The model treats each respondent as part of a population of similar respondents and then "borrows" information from the population to develop the part-worth utilities for each individual respondent [25].

Table 4 shows the result of the HB model, including the average utility values of the estimated model, the corresponding standard deviation values, and upper and lower 95\% confidence intervals.

The utilities are zero-centered, such that "the total sum of the differences in utility between the worst and best levels of each attribute across attributes is equal to the number of attributes times 100" [62]. Utilities indicate how favorable one attribute level is perceived over other attribute levels within the same attribute. Apart from the attribute investment costs, we chose the part-worth utility estimation function, in which a separate utility is estimated for each attribute level. To model the effect of investment costs on product choice, we estimated price as a continuous function by applying the linear coding method. To avoid an out-of-order utility relationship for the two attributes with an a priori preference order 
Table 2

Characteristics of the complete sample $(n=6104)$ in comparison with the structure of the Swiss population.

\begin{tabular}{lll}
\hline Characteristics & $\begin{array}{l}\text { Complete sample } \\
(\mathrm{n}=6104)-\mathrm{in} \%\end{array}$ & $\begin{array}{l}\text { Swiss average - } \\
\text { in\% }\end{array}$ \\
\hline $\begin{array}{l}\text { Gender }\left(\chi^{2}=0.003, \text { d.f. }=1, p=.960\right) \\
\text { Female }\end{array}$ & 51.0 & $51.0^{\mathrm{a}}$ \\
Male & 49.0 & $49.0^{\mathrm{a}}$ \\
Age $\left(\chi^{2}=0.025\right.$, d.f. $\left.=3, p=.999\right)$ & & \\
18-29 years & 18.3 & $18.3^{\mathrm{a}}$ \\
30-44 years & 26.0 & $26.0^{\mathrm{a}}$ \\
45-59 years & 27.3 & $27.3^{\mathrm{a}}$ \\
60-years & 28.3 & $28.4^{\mathrm{a}}$ \\
Language region $\left(\chi^{2}=1.479\right.$, d.f. $\left.=1, p=.224\right)$ & \\
German-speaking Switzerland & 75.0 & $75.7^{\mathrm{b}}$ \\
French-speaking Switzerland & 25.0 & $24.3^{\mathrm{b}}$ \\
Home ownership $\left(\chi^{2}=0.222\right.$, d.f. $\left.=1, p=.638\right)$ & \\
Homeowners & 43.5 & $43.8^{\mathrm{c}}$ \\
Tenants & 56.5 & $56.2^{\mathrm{c}}$ \\
\hline
\end{tabular}

Note: The results from chi-square tests are included in parentheses, which show whether significant differences between the overall study sample and the Swiss average could be identified.

a Source: Federal Statistical Office [58].

b Percentages refer to the German and French-speaking part of Switzerland and exclude the Italian-speaking part of Switzerland; Source: GfK [57].

c Source: Statista [68].

(i.e. investment costs; revenues from electricity sales/reduction in electricity costs over 20 years), we enforced constraints on orders of part-worths within those attributes. In addition, on the basis of the screening section choices, we estimated a separate utility weight for the "none" parameter, which we used in subsequent market simulations for the estimation of the proportion of respondents who would not opt for any of the simulated product concepts [25].
Table 3

Characteristics of the ACBC sample $(n=408)$ in comparison with the structure of the Swiss population.

\begin{tabular}{lll}
\hline Characteristics & $\begin{array}{l}\text { ACBC sample } \\
(\mathrm{n}=408)-\mathrm{in} \%\end{array}$ & $\begin{array}{l}\text { Swiss average }- \\
\text { in\% }\end{array}$ \\
\hline $\begin{array}{l}\text { Gender }\left(\chi^{2}=19.057, \text { d.f. }=1, p<.001\right) \\
\text { Female }\end{array}$ & 40.2 & $51.0^{\mathrm{a}}$ \\
Male & 59.8 & $49.0^{\mathrm{a}}$ \\
Age $\left(\chi^{2}=41.778\right.$, d.f. $\left.=3, p<.001\right)$ & & \\
18-29 years & 9.1 & $18.3^{\mathrm{a}}$ \\
30-44 years & 24.3 & $26.0^{\mathrm{a}}$ \\
$45-59$ years & 39.5 & $27.3^{\mathrm{a}}$ \\
60-years & 27.2 & $28.4^{\mathrm{a}}$ \\
Language region $\left(\chi^{2}=0.503\right.$, d.f. $\left.=1, p=.478\right)$ & \\
German-speaking Switzerland & 77.2 & $75.7^{\mathrm{b}}$ \\
French-speaking Switzerland & 22.8 & $24.3^{\mathrm{b}}$ \\
\hline
\end{tabular}

Source: [57]

Note: The results from chi-square tests are included in parentheses, which show whether significant differences between the overall study sample and the Swiss average could be identified.

a Source: [58].

b Percentages refer to the German and French-speaking part of Switzerland and exclude the Italian-speaking part of Switzerland.

\subsection{Calculation price premium for BIPV over rack-mounted PV}

As a next step, we conducted a simulated market scenario, using the calculated part-worth utilities of each respondent to estimate his or her likelihood of choosing a hypothetical product profile; we did this to calculate whether and how much more future residential roof renovators would be willing to pay for a roof with a BIPV plant than for a roof with a separate rack-mounted PV plant installed on top (see [11]. To calculate the premium for the BIPV roof retrofit option versus the rack-mounted PV roof retrofit option, we set up a simulation scenario with three options included (see Table 5). Option 1 and option 2 only differed with regard to the PV technol-

Table 4

Results of the HB model for the ACBC sample ( $n=408$ ).

\begin{tabular}{|c|c|c|c|c|}
\hline Attributes and levels & Average Utilities & $\mathrm{SD}^{\mathrm{a}}$ & Lower $95 \% \mathrm{Cl}^{\mathrm{b}}$ & Upper 95\% CI \\
\hline \multicolumn{5}{|l|}{ Roof type } \\
\hline BIPV & 51.64 & 49.38 & 46.83 & 56.44 \\
\hline Rack-mounted PV & 17.24 & 64.53 & 10.96 & 23.52 \\
\hline No PV & -68.88 & 73.83 & -76.07 & -61.70 \\
\hline \multicolumn{5}{|l|}{ Color of the PV plant/roof } \\
\hline Red & 33.86 & 58.85 & 28.13 & 39.59 \\
\hline Black & 16.24 & 44.33 & 11.93 & 20.55 \\
\hline Blue & -50.10 & 57.57 & -55.70 & -44.50 \\
\hline \multicolumn{5}{|l|}{ Origin of PV panels } \\
\hline Switzerland & 50.89 & 37.14 & 47.27 & 54.50 \\
\hline Germany & 21.83 & 24.98 & 19.39 & 24.26 \\
\hline China & -72.72 & 55.68 & -78.13 & -67.30 \\
\hline \multicolumn{5}{|l|}{ Investment costs } \\
\hline 10,000 Swiss Francs & 52.11 & 36.91 & 48.52 & 55.71 \\
\hline 50,000 Swiss Francs & -52.11 & 36.91 & -55.71 & -48.52 \\
\hline \multicolumn{5}{|c|}{ Revenues from electricity sales/reduction in electricity costs over 20 years } \\
\hline$-40,000$ Swiss Francs & 25.90 & 14.90 & 24.45 & 27.35 \\
\hline$-30,000$ Swiss Francs & -3.87 & 5.88 & -4.44 & -3.30 \\
\hline$-20,000$ Swiss Francs & -22.03 & 15.96 & -23.59 & -20.48 \\
\hline \multicolumn{5}{|l|}{ Purchase premium } \\
\hline Free e-Bike & 1.21 & 8.64 & 0.37 & 2.05 \\
\hline Participating in e-car raffle (Tesla) & 0.21 & 12.22 & -0.98 & 1.40 \\
\hline Rebate of $1000 \mathrm{CHF}$ & -1.43 & 10.54 & -2.45 & -0.40 \\
\hline None & 23.30 & 66.34 & 16.85 & 29.76 \\
\hline
\end{tabular}

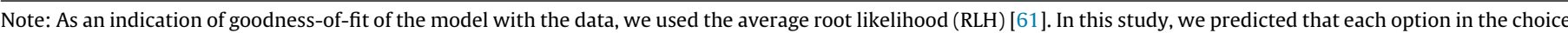

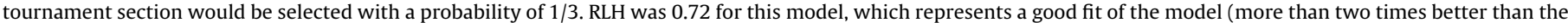
chance level).

\footnotetext{
a $\mathrm{SD}=$ Standard deviation

b $\mathrm{CI}=$ Confidence interval.
} 
Table 5

Determination of price premium via market simulation.

\begin{tabular}{|c|c|c|c|}
\hline & Option 1 & Option 2 & Option 3 \\
\hline Roof type & BIPV & Rack-mounted PV & Would not choose any \\
\hline Color of the PV plant/roof & Red & Red & of those options \\
\hline Origin of PV panels & Switzerland & Switzerland & \\
\hline Investment costs & $48,715 \mathrm{CHF}$ & $40,000 \mathrm{CHF}$ & \\
\hline Revenues from electricity sales/reduction in electricity costs over 20 years & $-40,000 \mathrm{CHF}$ & $-40,000 \mathrm{CHF}$ & \\
\hline Purchase premium & Free e-bike & Free e-bike & \\
\hline Simulated share of preference & $44.29 \%$ & $44.29 \%$ & $13.42 \%$ \\
\hline
\end{tabular}

Table 6

Base case scenario for the sensitivity analyses.

\begin{tabular}{|c|c|c|c|}
\hline & \multicolumn{3}{|c|}{ Base case scenario } \\
\hline & Option 1 & Option 2 & Option 3 \\
\hline Roof type & BIPV & Rack-mounted PV & Would not choose any \\
\hline Color of the PV plant & Blue & Blue & of those options \\
\hline Origin of PV panels & China & China & \\
\hline Investment costs & $40,000 \mathrm{CHF}$ & $40,000 \mathrm{CHF}$ & \\
\hline Revenues from electricity sales/reduction in electricity costs over 20 years & $-20,000 \mathrm{CHF}$ & $-20,000 \mathrm{CHF}$ & \\
\hline Purchase premium & Rebate & Rebate & \\
\hline Individual simulated share of preference of PV options & $15.42 \%$ & $9.16 \%$ & $75.42 \%$ \\
\hline Aggregated simulated share of preference of PV options & $24.58 \%$ & & $75.42 \%$ \\
\hline
\end{tabular}

ogy installed on the roof (rack-mounted PV vs. BIPV) and the level of investment costs, whereas we set the other attributes (i.e. color of the PV plant, country of origin of the PV plant, revenues from electricity sales/reduction in electricity costs over 20 years, and purchase premium) at the identical level. We also included a third option ("None"), to predict the share of respondents who would not choose either of the two offered options. The market simulator would simulate that the "None" option would be chosen if the utilities of the other two options did not exceed the "None" utility threshold as calculated in the HB estimation. We subsequently increased the level of investment costs for the BIPV option until no difference in the simulated share of preference between the BIPV and the rack-mounted PV roof retrofit options was found. We took the difference in the level of investment costs as the premium homeowners would be willing to pay for a roof retrofit where a BIPV plant would be installed on their roof in comparison with a roof retrofit where a rack-mounted PV plant would be installed on the roof. We find that, on average, the roof option with a BIPV plant could cost $8715 \mathrm{CHF}$, or $21.79 \%$, more than a roof with a rack-mounted PV plant.

\subsection{Sensitivity analyses to observe changes in shares of preference due to changing PV-specific specifications}

As a next step, we conducted sensitivity analyses with the Sawtooth market simulator, making use of the estimated part-worth utilities from the HB estimation to perform a series of simulation scenarios, to estimate how much the demand, or share of preference, for PV among residential homeowners in Switzerland would change from altering product specifications (see [63]. In the sensitivity runs making use of the share of preference model, we changed the level of one attribute (e.g. the color of the PV panels) and estimated how the change of that specific attribute affected the overall share of preference for PV among our surveyed respondents, while keeping all the other attribute levels at a constant level.

We achieved this by defining a specific "base case" scenario in terms of the attributes and levels used in the study. We again included three different options in this scenario. Option 1 (BIPV) and option 2 (rack-mounted PV) differed only in the technology installed on the roof. We set the other attributes at the levels with the lowest average utilities for the attributes color of the PV plant (i.e. blue), origin of PV panels (i.e. China), revenues from electricity sales/reduction in electricity costs over 20 years (i.e. 20,000 CHF), and the purchase premium (i.e. rebate). We set the price for both options 1 and 2 at 40,000 CHF. We also included a "None" option. Table 6 describes the base case scenario.

Then, we altered one attribute level in both options 1 and 2, while keeping all other levels constant at those of the base case scenario. The market simulation then calculated the percentage of respondents who would choose either the BIPV or the rackmounted PV roof retrofit option and the percentage of respondents who would not choose either of the two options. A change in share of preference for PV among residential homeowners in Switzerland is a direct result of altering the PV's product characteristics. Table 6 shows the results for the base case scenario. Under this scenario, only $15.42 \%$ of the respondents would opt for the BIPV roof retrofit option, $9.16 \%$ would choose the retrofit option with a rack-mounted PV plant installed, and $75.42 \%$ would not choose either of the two simulated options.

As a next step, we made adjustments to the base case by changing individual specifications, to evaluate how specific changes influence the percentage of homeowners choosing the PV roof retrofit options versus not choosing it (i.e. choosing the "None" option). For example, in one simulation scenario, we changed the color of the PV roof retrofit options while keeping all other settings constant. By doing so, we can discern whether a different color of the PV panels would affect the share of preference positively for PV among homeowners in Switzerland. Fig. 4 present changes in predicted choice probabilities based on those simulations.

The results reveal that changing the color of the PV panels leads to substantial increases in the percentage of respondents preferring a roof retrofit option with a PV installation in comparison with the "None" option. More specifically, offering PV panels in the colors black and red, instead of the classic color blue, would increase the share of preference for PV among Swiss homeowners by 13.01 and 17.83 percentage points, respectively.

The main driver for enhanced demand for PV would however be altering the country of origin of the PV panels. More specifically, in cases in which manufacturers offering PV panels were from Germany or Switzerland (vs. China), the results show that PV would become a real alternative to choosing a conventional roof without any PV plant installed. That is, the results reveal that offering the PV panels from Germany or Switzerland would create a potential market share for PV among Swiss homeowners by additional 19.03 


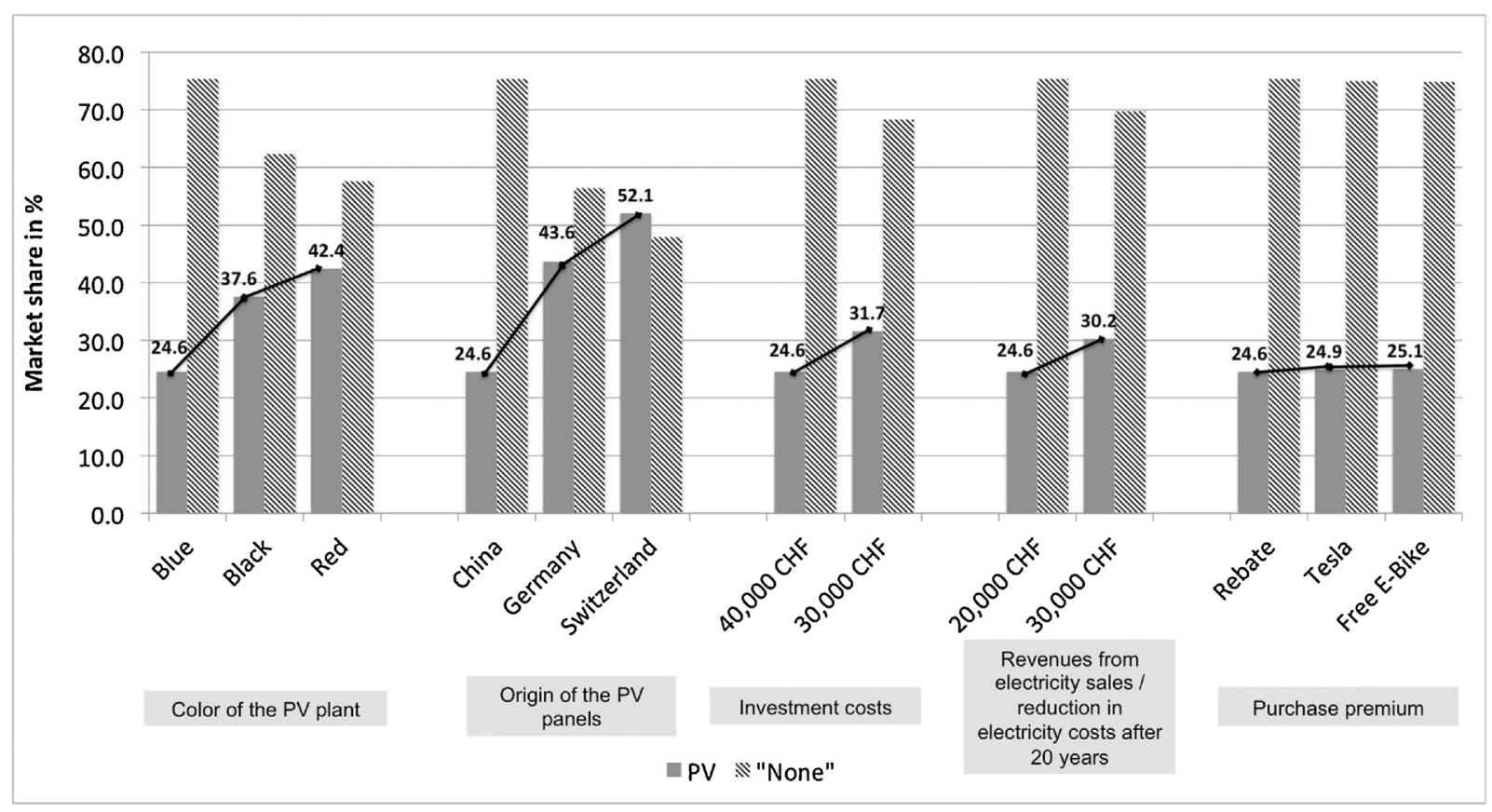

Fig. 4. Sensitivity analyses to observe change in share of preferences for PV among Swiss homeowners due to changing specifications.

Table 7

"Best case" scenario.

\begin{tabular}{|c|c|c|c|}
\hline & \multicolumn{3}{|c|}{ "Best case" scenario } \\
\hline & Option 1 & Option 2 & Option 3 \\
\hline Roof type & BIPV & Rack-mounted PV & Would not choose any \\
\hline Color of the PV plant & Red & Red & of those options \\
\hline Origin of PV panels & Switzerland & Switzerland & \\
\hline Investment costs & $30,000 \mathrm{CHF}$ & $30,000 \mathrm{CHF}$ & \\
\hline Revenues from electricity sales/reduction in electricity costs over 20 years & $-40,000 \mathrm{CHF}$ & $-40,000 \mathrm{CHF}$ & \\
\hline Purchase premium & E-bike & E-bike & \\
\hline Individual simulated share of preference of PV options & $55.02 \%$ & $34.75 \%$ & $10.23 \%$ \\
\hline Aggregated simulated share of preference of PV options & $89.77 \%$ & & $10.23 \%$ \\
\hline
\end{tabular}

and 27.50 percentage points compared with offering the PV panels from China, respectively. Thus, we find that Swiss customers prefer PV panels produced from European manufacturers. In addition, homeowners also prefer PV panels produced in Switzerland to panels produced in Germany.

Furthermore, we find that offering different purchase premiums do not result in substantial increases in the percentage of homeowners preferring a PV roof retrofit option. However, we identify subtle differences between the different types of purchase premiums. More precisely, offering the possibility to win an electric car of the brand Tesla increases the percentage of homeowners preferring the BIPV option by 0.35 percentage points, while offering a free e-bike increases the percentage of homeowners preferring the BIPV option by 0.48 percentage points, versus the baseline effect of offering a rebate of $1000 \mathrm{CHF}$.

Furthermore, we show that a decrease in electricity costs by not purchasing electricity from the grid or an increase in potential revenues from selling self-produced power to the grid through feed-in tariffs by $10,000 \mathrm{CHF}$ (from $20,000 \mathrm{CHF}$ to $30,000 \mathrm{CHF}$ ) over a period of 20 years would increase the percentage of homeowners preferring a PV roof retrofit option by 5.65 percentage points. In contrast, our results reveal that reducing the investment costs could also foster the further adoption of PV in Switzerland. A decrease of the investment costs from 40,000 CHF to 30,000 CHF would raise the likelihood of opting for a PV roof retrofit option in Switzerland by 7.07 percentage points compared with the baseline scenario. Thus, the results indicate that the shares of preferences are slightly more sensitive to changes in investment costs than to changes in possible reduction in electricity costs or revenues from electricity sales. However, this difference (5.65 vs. 7.07 percentage points) is not very pronounced, indicating that when such monetary information is displayed aggregated over a period of 20 years, the increase in the level of revenues from electricity sales (which policy makers can influence through feed-in tariffs) could be almost equally powerful to increase market share for PV among Swiss homeowners as a decrease in upfront investment costs (which could be reduced by a one-off investment grant).

\subsection{Potential market share of PV among Swiss homeowners under the "best case" scenario}

Finally, we determined the market share of PV that could be achieved in Switzerland in a scenario in which all features would be varied simultaneously in a way to better meet homeowners' preferences. This "best-case" scenario included two PV options, including option 1 (BIPV) and option 2 (rack-mounted PV). Both options were based on the levels with the highest average utility ratings for the attributes color of PV plant (i.e. red), origin of PV panels (i.e. Switzerland), revenues from electricity sales/reduction in electricity costs over 20 years (i.e. 40,000 CHF), and the purchase premium (i.e. e-bike). We set the price for the base case PV options at 30,000 CHF (i.e. 10,000 CHF lower than under the base case scenario as 
described in Table 6), assuming that a one-off investment grant of $10,000 \mathrm{CHF}$ was introduced. We also included a "None" option as described previously (see Table 7 for all roof options included in the scenario). Under this scenario, $89.77 \%$ of the respondents would opt for one of the two PV roof retrofit options. Thus, our results show that PV could be successfully adopted among Swiss homeowners given favorable conditions.

\section{Conclusions and policy and marketing implications}

First, by performing an ACBC survey, our results suggest a strong business case for BIPV in Switzerland. We show that private homeowners would be willing to pay a premium of $21.79 \%$ for a roof with a BIPV plant installation versus a roof with a rack-mounted PV plant installation, all else being equal (e.g. color, origin of PV panels). As such, producers and installers of BIPV plants could differentiate themselves on the basis of the increased value (e.g. aesthetics) that BIPV provides for homeowners.

Second, we find evidence that particularly the color and the country-of-origin declaration of a PV plant can be crucial drivers in increasing potential market share for PV (both BIPV and rack-mounted PV) in Switzerland. In more detail, we find that homeowners would favor PV panels in the colors red and black instead of blue, which is still the standard color used for most PV installations. This finding is promising for architects who have been hesitant to fully embrace traditional blue-colored PV technology, due to poor panel aesthetics. With new ways for aesthetical integration of PV, our results should encourage architects to adopt the new technologies to a larger extent, as the reward for doing so in terms of meeting customer preferences proves promising. Furthermore, our results are highly relevant for policy makers who are trying both to reduce the environmental impact of the housing stock and to protect and preserve monuments and historic buildings. Introducing measures that lower the administrative barriers for PV installations that provide the opportunity for a more upscale architectural design would enable the simultaneous achievement of both policy goals.

Third, Swiss homeowners prefer European PV panels to Chinese PV panels. Given that both Germany and Switzerland have a high reputation for the production of technical goods [42], we leave it up to further research to investigate whether homeowners used the country-of-origin information as a shortcut to indirectly infer the products' quality characteristics, such as durability. In addition, the results reveal that homeowners prefer PV panels produced in Switzerland to PV panels produced in Germany. This finding indicates that homeowners' preferences for PV panels from Switzerland could be due to the affective or normative meaning that the country-of-origin information conveys to Swiss homeowners. Previous studies have shown that disclosing the country of origin can have an affective meaning to people, due to the emotional connotations people have with a specific country or due to the normative meaning when people view purchasing local goods as a way to support the local economy $[39,64]$. The identification of preferences of Swiss consumers for locally produced PV panels from Switzerland over German PV panels is in line with previous findings from the renewable energy literature that also reveals Swiss citizens' strong preference for Swiss over German ownership of hydropower plants [65]. This strong preference should encourage manufacturers from Switzerland to emphasize the Swiss origin of the panels in their marketing efforts to differentiate themselves on the basis of the country-of-origin effect. Furthermore, this finding could support policy makers in Switzerland in their effort to assist the small local PV industry and to introduce start-up-friendly policies.

Fourth, we find that a decrease in investment costs and an increase in revenues from selling self-produced electricity to the grid (when aggregated over a period of 20 years) of the same magnitude would lead to an almost equal increase in demand for PV among homeowners in Switzerland. These findings are in line with prior studies that have shown that aggregating future energy costs or savings over a longer period (e.g. lifetime of a product), versus providing this information per year, can significantly encourage people to take that information into account in their purchasing decisions, as it enables people to realize the sheer size of the possible savings (e.g. [47,48,66,67]. The findings of the current study also have high political relevance. Our simulations show that certain forms of governmental support such as feed-in tariffs to increase revenues from selling self-produced electricity to the grid over a longer period, when transparently disclosed over an aggregated time frame, can lead to an almost equal increase in market share of PV as one-off grants to lower investment costs.

As with any research, the results are subject to several limitations, given that the choices were made under a hypothetical scenario in which people were not required to actually pay the investment costs of the roof renovation option they chose. In addition, although we show future revenues from electricity sales or reductions in electricity costs as a stable flow of revenues, they are subject to uncertainties in real life in terms of the cost of electricity prices, technical risks, and so on. As a further point of consideration, we visualized three attributes in the $A C B C$ via conditional displays (roof type, color, and purchase premium) that might have attracted more attention to the attributes on costs and savings and the origin of PV panels, which were presented in text form. Thus, the tendency to neglect the pricing attribute must be acknowledged with this type of surveying technique. Finally, we did not randomize the attribute order (i.e. attributes appeared in their natural and not in random order within the concept). Therefore, we cannot exclude that a systematic order effect might have occurred.

\section{Acknowledgements}

This article is based on the interdisciplinary research project ACTIVE INTERFACES (www.activeinterfaces.ch). The research project is part of the National Research Program "Energy Turnaround" (NRP 70) of the Swiss National Science Foundation. Further information on the National Research Program is available at www.nrp70.ch. This research is also part of the activities of SCCER CREST (Swiss Competence Center for Energy Research), which is financially supported by the Swiss Commission for Technology and Innovation (CTI).

\section{Appendix A}




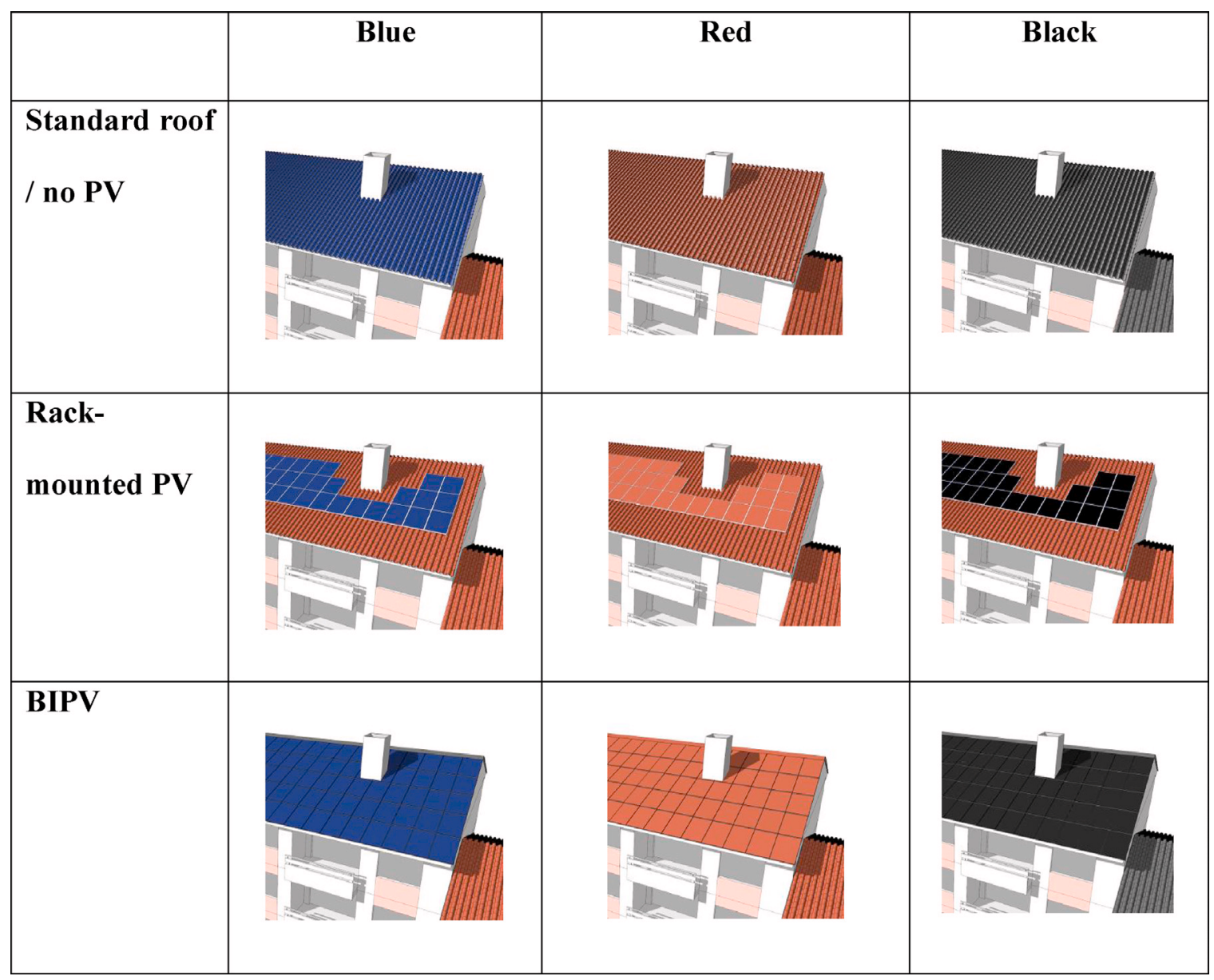

Fig. A1. Conditional displays based on nine possible combinations of the two attributes 'roof type' and "color".

\section{References}

[1] IPCC, Climate change 2014, in: Synthesis Report, 2014 (Summary for Policymakers: Intergovernmental Panel on Climate Change).

[2] IEA, Key renewables trends, in: Excerpt from - Renewables Information, International Energy Agency, 2016.

[3] IEA, Energy policies of IEA countries, in: Switzerland. 2012 Review, International Energy Agency, 2012.

[4] O. Temby, K. Kapsis, H. Berton, D. Rosenbloom, G. Gibson, A. Athienitis, J. Meadowcroft, Building-integrated photovoltaics: distributed energy development for urban sustainability, Environ.: Sci. Policy Sustain. Dev. 56 (6) (2014) 4-17.

[5] IEA, Potential for Building Integrated Photovoltaics, Vol. PVPS T7-4, International Energy Agency, 2002.

[6] P. Drachman, K.A. Adamson, Building Integrated Photovoltaics. Report of PikeResearch, 2012 (Retrieved from http://www.navigantresearch.com/ wordpress/wp-content/uploads/2012/08/BIPV-12-Executive-Summary-2. pdf).

[7] J. Koinegg, T. Brudermann, A. Posch, M. Mrotzek, It would be a shame if we did not take advantage of the spirit of the times ... an analysis of prospects and barriers of building integrated photovoltaics, Gaia-Ecol. Perspect. Sci. Soc. 22 (1) (2013) 39-45

[8] Nanomarkets, BIPV Markets Analysis and Forecasts 2014-2021, 2014 (Retrieved 17 July 2014, from http://nanomarkets.net/market_reports/report/ bipv-markets-analysis-and-forecasts-2014-2021).

[9] J. Urbanetz, C.D. Zomer, R. Rüther, Compromises between form and function in grid-connected, building-integrated photovoltaics (BIPV) at low-latitude sites, Build. Environ. 46 (10) (2011) 2107-2113.

[10] H.C. Curtius, The Adoption of Building-Integrated Photovoltaics: Barriers and Facilitators, University of St.Gallen. Working paper, 2017.

[11] B. Orme, Getting Started with Conjoint Analysis: Strategies for Product Design and Pricing Research, second ed., Research Publishers, Madison, WI, 2010.

[12] C.K. Chau, M.S. Tse, K.Y. Chung, A choice experiment to estimate the effect of green experience on preferences and willingness-to-pay for green building attributes, Build. Environ. 45 (11) (2010) 2553-2561.

[13] H.D. Cheung, T.M. Chung, A study on subjective preference to daylit residential indoor environment using conjoint analysis, Build. Environ. 43 (12) (2008) 2101-2111.
[14] S. Darshing, S. Hille, The energy paradox revisited: analyzing the role of individual differences and framing effects in information perception, J. Consum. Policy 40 (4) (2017) 485-508.

[15] S. Darshing, S. Hille, R. Wüstenhagen, The influence of political orientation on the strength and temporal persistence of policy framing effects, Ecol. Econ. 142 (2017) 295-305

[16] N. Hampl, M. Loock, Sustainable development in retailing: what is the impact on store choice? Bus. Strat. Environ. 22 (3) (2013) 202-216.

[17] S.L. Heinzle, R. Wüstenhagen, Dynamic adjustment of eco-labeling schemes and consumer choice-the revision of the EU energy label as a missed opportunity? Bus. Strat. Environ. 21 (1) (2012) 60-70

[18] J. Kaenzig, S.L. Heinzle, R. Wüstenhagen, Whatever the customer wants, the customer gets? Exploring the gap between consumer preferences and default electricity products in Germany, Energy Policy 53 (2013) 311-322.

[19] O.E. Mansour, S.K. Radford, Rethinking the environmental and experiential categories of sustainable building design, a conjoint analysis, Build. Environ. 98 (2016) 47-54.

[20] M. Park, A. Hagishima, J. Tanimoto, C. Chun, Willingness to pay for improvements in environmental performance of residential buildings, Build. Environ. 60 (2013) 225-233.

[21] K. Sammer, R. Wüstenhagen, The influence of eco-labelling on consumer behaviour -results of a discrete choice analysis for washing machines, Bus. Strat. Environ. 15 (2006) 185-199.

[22] A. Tabi, S.L. Hille, R. Wüstenhagen, What makes people seal the green power deal?-Customer segmentation based on choice experiment in Germany, Ecol. Econ. 107 (2014) 206-215.

[23] D.W. Thompson, R.C. Anderson, E.N. Hansen, L.R. Kahle, Green segmentation and environmental certification: insights from forest products, Bus. Strat. Environ. 19 (5) (2010) 319-334.

[24] R.M. Johnson, B.K. Orme, A new approach to adaptive CBC, in: Sawtooth Software Conference Proceedings, Sequim, WA, 2007.

[25] Sawtooth Software, ACBC Technical Paper, 2014 https://www. sawtoothsoftware.com/support/technical-papers/adaptive-cbc-papers/acbctechnical-paper-2009.

[26] I. Boesch, M. Weber, Processor's preferences and basic differentiation strategies for potatoes, milk, and wheat in Switzerland, J. Agric. Food Indus. Organ. 10 (1) (2012) 1-22. 
[27] C.E. Cunningham, K. Deal, Y. Chen, Adaptive choice-based conjoint analysis, Patient: Patient-Center. Outcomes Res. 3 (4) (2010) 257-273.

[28] S.L. Heinzle, A.B.Y. Yip, M.L.Y. Xing, The influence of green building certification schemes on real estate investor behaviour: evidence from Singapore, Urban Stud. 50 (4) (2013) 1-18

[29] G. Hinnen, S.L. Hille, A. Wittmer, Willingness to Pay for Green Products in Air Travel: Ready for Take-Off? Business Strategy and the Environment, Early View, 2015.

[30] S. Lüthi, T. Prässler, Analyzing policy support instruments and regulatory risk factors for wind energy deployment-A developers' perspective, Energy Policy 39 (9) (2011) 4876-4892.

[31] S. Salm, S.L. Hille, R. Wüstenhagen, What are retail investors' risk-return preferences towards renewable energy projects? A choice experiment in Germany, Energy Policy 97 (2016) 310-320.

[32] N. Lynn, L. Mohanty, S. Wittkopf, Color rendering properties of semi-transparent thin-film PV modules, Build. Environ. 54 (2012) 148-158

[33] P. Heinstein, C. Ballif, L.E. Perret-Aebi, Building integrated photovoltaics (BIPV): review, potentials, barriers and myths, Green 3 (2) (2013) 125-156.

[34] W.J. Bilkey, E. Nes, Country-of-origin effects on product evaluations, J. Int. Bus Stud. 13 (1) (1982) 89-100.

[35] J. Bloemer, K. Brijs, H. Kasper, The CoO-ELM model: a theoretical framework for the cognitive processes underlying country of origin-effects, Eur. J. Market. $43(1 / 2)(2009) 62-89$.

[36] M. Chattalas, T. Kramer, H. Takada, The impact of national stereotypes on the country of origin effect: a conceptual framework, Int. Market. Rev. 25 (1) (2008) 54-74

[37] R.A. Peterson, A.J. Jolibert, A meta-analysis of country-of-origin effects, J. Int. Bus. Stud. 26 (1995) 883-900.

[38] S. Samiee, Customer evaluation of products in a global market, J. Int. Bus. Stud. 25 (1994) 579-604.

[39] P.W. Verlegh, J.B.E. Steenkamp, A review and meta-analysis of country-of-origin research, J. Econ. Psychol. 20 (5) (1999) 521-546.

[40] J. Johansson, Determinants and effects of the use of made in labels, Int Market. Rev. 6 (1) (1989) 47-58

41] R. Veale, P. Quester, Do consumer expectations match experience? Predicting the influence of price and country of origin on perceptions of product quality, Int. Bus. Rev. 18 (2) (2009) 134-144.

[42] Swissness Worldwide, Image Und Internationaler Mehrwert Der Marke Schweiz, Universität St. Gallen; htp St. Gallen Managementberatung AG, Jung von Matt/Limmat, 2016 (A study by Stephan Feige, Raphael Annen, Dominique von Matt and Sven Reinecke).

[43] S. Frederick, G. Loewenstein, T. O’Donoghue, Time discounting and time preference: a critical review, J. Econ. Lit. 40 (2002) 351-401.

[44] J. Hausman, Individual discount rates and the purchase and utilization of energy-using durables, Bell J. Econ. 10 (1979) 33-54

[45] A.B. Jaffe, R.N. Stavins, The energy paradox and the diffusion of conservation technology, Res. Energy Econ. 16 (2) (1994) 91-122.

[46] K. Train, Discount rates in consumers' energy-related decisions: a review of the literature, Energy 10 (1985) 1243-1253.

[47] S.L. Heinzle, Disclosure of energy operating cost information: a silver bullet for overcoming the energy-efficiency gap? J. Consum. Policy 35 (1) (2012) 43-64.

[48] J. Kaenzig, R. Wüstenhagen, The effect of life cycle cost information on consumer investment decisions regarding eco-innovation, J. Ind. Ecol. 14 (1) (2010) 121-136.
[49] S.D. Halpern, R. Kohn, A. Dornbrand-Lo, T. Metkus, D.A. Asch, K.G. Volpp, Lottery-based versus fixed incentives to increase clinicians' response to surveys, Health Serv. Res. 46 (5) (2011) 1663-1674

[50] D. Kahneman, A. Tversky, Prospect theory: an analysis of decision under risk, Econometr.: J. Economet. Soc. 47 (1979) 263-291.

[51] E. Haisley, K.G. Volpp, T. Pellathy, G. Loewenstein, Promoting completion of health risk assessments with lottery incentives, Am. J. Health Promot. 26 (3) (2012) 184-188

[52] N.M. Petry, S.M. Alessi, J. Marx, M. Austin, M. Tardif, Vouchers vs. prizes: contingency management treatment of substance abusers in community settings, J. Consult. Clin. Psychol. 73 (2005) 1005-1014.

[53] N.M. Petry, S.M. Alessi, T. Hanson, S. Sierra, Randomized trial of contingent prizes versus vouchers in cocaine-using methadone patients, J. Consult. Clin. Psychol. 75 (2007) 983-991.

[54] C. Anderson, Free: the future of a radical price, Hyperion, NY., Baker, MJ, Ballington, L., 2002. country of origin as a source of competitive advantage, J. Strat. Market. 10 (2) (2009) 157-168.

[55] J.L. Nicolau, R. Sellers, The free breakfast effect: an experimental approach to the zero price model in tourism, J. Travel Res. 51 (3) (2012) 243-249.

[56] K. Shampanier, N. Mazar, D. Ariely, Zero as a special price: the true value of free products, Market. Sci. 26 (6) (2007) 742-757.

[57] GfK, Vademecum 2013, 2013 (37. Jahrgang. GfK Switzerland AG.).

[58] Federal Statistical Office, Ständige Wohnbevölkerung Nach Geschlecht, 2015 https://www.bfs.admin.ch/bfs/de/home/statistiken/bevoelkerung.html.

[59] J. Huber, K. Train, On the similarity of classical and Bayesian estimates of individual mean partworths, Market. Lett. 12 (2001) 259-269.

[60] P.E. Rossi, G.M. Allenby, Bayesian statistics and marketing, Market. Sci. 22 (2003) 304-328

[61] Sawtooth Software, The CBC/HB System for Hierarchical Bayes Estimation Version 5.0 Technical Paper, 2009 https://www.sawtoothsoftware.com/ support/technical-papers/hierarchical-bayes-estimation/cbc-hb-technicalpaper-2009.

[62] Sawtooth Software, HB Estimation, 2015 https://www.sawtoothsoftware. com/help/issues/ssiweb/online_help/generalhbestimation.htm.

[63] Sawtooth Software, Sensitivity Analysis, 2016 https://www. sawtoothsoftware.com/help/lighthouse-studio/manual/ sensitivitysettingswindow.html.

[64] T.A. Shimp, S. Sharma, Consumer ethnocentrism: construction and validation of the CETSCALE, J. Market. Res. 24 (1987) 280-289.

[65] A. Tabi, R. Wüstenhagen, Keep It Local and Fish-Friendly: Social Acceptance of Hydropower Projects in Switzerland, 2016 (Under review).

[66] J. Bull, Loads of green washing-can behavioural economics increase willingness-to-pay for efficient washing machines in the UK? Energy Policy 50 (2012) 242-252

[67] M. Deutsch, Life cycle cost disclosure, consumer behavior, and business implications, J. Ind. Ecol. 14 (1) (2010) 103-120.

[68] Statista, Verteilung der Bevölkerung in der Schweiz von 2010 bis 2014 nach Mieter und Eigentümer, 2011 http://de.statista.com/statistik/daten/studie/ 370719/umfrage/bevoelkerung-in-der-schweiz-nach-mieter-undeigentuemer/. 